\section{Commentary: Early failure of the Trifecta GT bioprosthesis: Innovation is not always progress}

\author{
Jean Porterie, MD, \\ Dimitri Kalavrouziotis, MD, FRCSC, and \\ Siamak Mohammadi, MD, FRCSC
}

Structural valve degeneration (SVD) is a major disadvantage of surgical aortic valve replacement (AVR) with a bioprosthesis. A recent single-center series demonstrated that the Trifecta valve (Abbott Vascular, Santa Clara, Calif) can be safely implanted in the aortic position with excellent hemodynamics and midterm durability, ${ }^{1}$ whereas others have shown unusually high early SVD rates with this prosthesis. ${ }^{2}$ The newer-generation Trifecta with Glide Technology (GT) was designed to improve these results, using novel antileaflet calcification and anti-support strut distortion technology.

In this issue of the Journal, Tchouta and colleagues ${ }^{3}$ reported 3 cases of early SVD after AVR with the Trifecta GT, for a cumulative incidence of $3.3 \%$ at 3.5 years among a population of 106 patients. Mean age at implantation was 56.7 years and all 3 patients had bicuspid aortic valve. The SVD occurred between 1.9 and 3.2 years after implantation, and all patients presented with aortic insufficiency and heart failure. There was no patient-prosthesis mismatch and endocarditis. All patients underwent redo AVR, and intraoperative findings were similar in the 3 cases, namely a detached prosthetic leaflet at the stent post between the noncoronary and right coronary cusps, without leaflet calcification. The authors postulated that the externally mounted leaflet design of the Trifecta GT and mechanical abrasion

From the Division of Cardiac Surgery, Quebec Heart and Lung Institute, Laval University, Quebec City, Quebec, Canada.

Disclosures: Dr Porterie received a grant from Edwards Lifesciences for his fellowship training at the Quebec Heart and Lung Institute. All other authors reported no conflicts of interest.

The Journal policy requires editors and reviewers to disclose conflicts of interest and to decline handling or reviewing manuscripts for which they may have a conflict of interest. The editors and reviewers of this article have no conflicts of interest.

Received for publication Sept 5, 2020; revisions received Sept 5, 2020; accepted for publication Sept 24, 2020; available ahead of print Sept 28, 2020.

Address for reprints: Siamak Mohammadi, MD, FRCSC, Department of Cardiac Surgery, Quebec Heart and Lung Institute, 2725 chemin Sainte-Foy, Quebec City, Quebec, Canada G1V 4G5 (E-mail: siamak.mohammadi@fmed.ulaval.ca).

JTCVS Techniques 2020;4:109-10

2666-2507

Copyright (C) 2020 The Authors. Published by Elsevier Inc. on behalf of The American Association for Thoracic Surgery. This is an open access article under the CC BY-NCND license (http://creativecommons.org/licenses/by-nc-nd/4.0/).

https://doi.org/10.1016/j.xjtc.2020.09.033

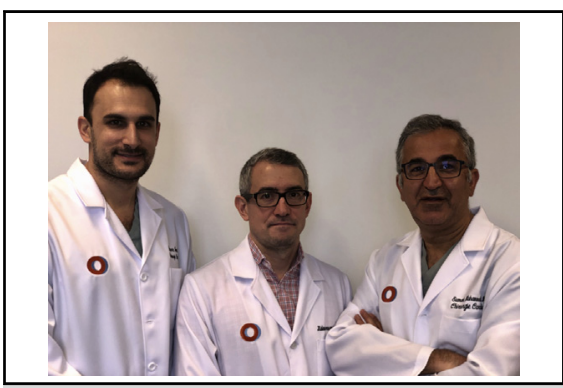

Jean Porterie, MD, Dimitri Kalavrouziotis, MD FRCSC, and Siamak Mohammadi, MD, FRCSC

CENTRAL MESSAGE

There is an urgent need to elucidate all possible mechanisms of early and late prosthetic valve failure, especially as treatment options for severe aortic stenosis continue to rapidly evolve.

from the aortic wall may have contributed to the early failure of the prosthesis.

The report by Tchouta and colleagues ${ }^{3}$ suggests that biologic/immunologic factors may be less relevant in early SVD, whereas the mechanical/fluid dynamic properties directly associated with particular elements of the prosthetic valve design may be more important contributing factors. ${ }^{2,4}$ No prosthetic leaflet calcification was observed in any of the 3 cases. Conversely, the leaflet disinsertion found at the same location in all patients was also observed in a majority of the cases of SVD presenting with pure aortic insufficiency occurring on the first-generation Trifecta prosthesis. ${ }^{2}$ In vitro fluid dynamic studies have shown that the externally mounted design of the Trifecta valve is associated with favorable hemodynamic properties compared with other stented bioprostheses, in which leaflets are mounted internally, including a lower resistance to flow and a larger effective orifice area. However, a greater degree of prosthetic leaflet flutter was observed with the Trifecta prosthesis. ${ }^{5}$ The Mitroflow valve (LivaNova Group Inc, London, England), another bioprosthesis in which the leaflets are externally-mounted, is well-known to have high rates of accelerated SVD. ${ }^{6}$ Another hypothesis is that the asymmetrical aortic annulus of bicuspid aortic valve may have increased the likelihood of abnormal shear-stress patterns and may potentially explain the monomorphic nature of the observed prosthetic failures. The implant technique itself may have a major impact in the durability of 
prostheses with externally mounted leaflets, including oversizing, bending of the strut posts during hand-tying of sutures, or the use of suture-tying devices with rigid knot stabilizers. Although oversizing was unlikely to play a significant role in the SVD reported by Tchouta and colleagues, ${ }^{3} 2$ of the 3 patients required an aortic annulus enlargement, and the third was a female with small body surface area and aortic root diameter, suggesting anatomical conditions likely to favor strut distortion during implantation.

In summary, the findings by Tchouta and colleagues ${ }^{3}$ are concerning, especially given the current trend of extending bioprosthetic AVR to younger patients. Well-designed, multicenter studies are urgently needed to elucidate all possible mechanisms of early SVD, to allow for a finetuning of the surgical implant, and optimal selection of the appropriate prosthesis for each individual patient. The report by Tchouta and colleagues ${ }^{3}$ further highlights the fact that close longitudinal echocardiographic surveillance becomes paramount in an era in which the treatment of severe aortic stenosis is rapidly evolving.

\section{References}

1. Kilic A, Sultan I, Navid F, Aranda-Michel E, Chu D, Thoma F, et al. Trifecta aortic bioprosthesis: midterm results in 1,953 patients from a single center. Ann Thorac Surg. 2019;107:1356-62.

2. Fukuhara S, Shiomi S, Yang B, Kim K, Bolling SF, Haft J, et al. Early structural valve degeneration of trifecta bioprosthesis. Ann Thorac Surg. 2020;109: 720-7.

3. Tchouta L, Liesman D, Kim K, Fukuhara S. Early failure of the Trifecta GT bioprostheses. J Thorac Cardiovasc Surg Tech. 2020;4:106-8.

4. Gallo M, Demertzis S. Xenoantigens and structural valve degeneration of Trifecta bioprosthesis: connecting the dots. Ann Thorac Surg. 2020;110:343.

5. Marx P, Kowalczyk W, Demircioglu A, Shehada S-E, Wendta H, Mourad F, et al. An in vitro comparison of flow dynamics of the Magna Ease and the Trifecta prostheses. Minim Invasive Ther Allied Technol. 2020;29:78-85.

6. Ius F, Schulz J, Roumieh M, Fleissner F, Ismail I, Tudorache I, et al. Long-term results of the Mitroflow aortic pericardial bioprosthesis in over 800 patients: limited durability and mechanisms of dysfunction. Eur J Cardiothorac Surg. 2017;52:264-71. 